International Journal of Medical Anesthesiology 2019; 2(2): 182-186

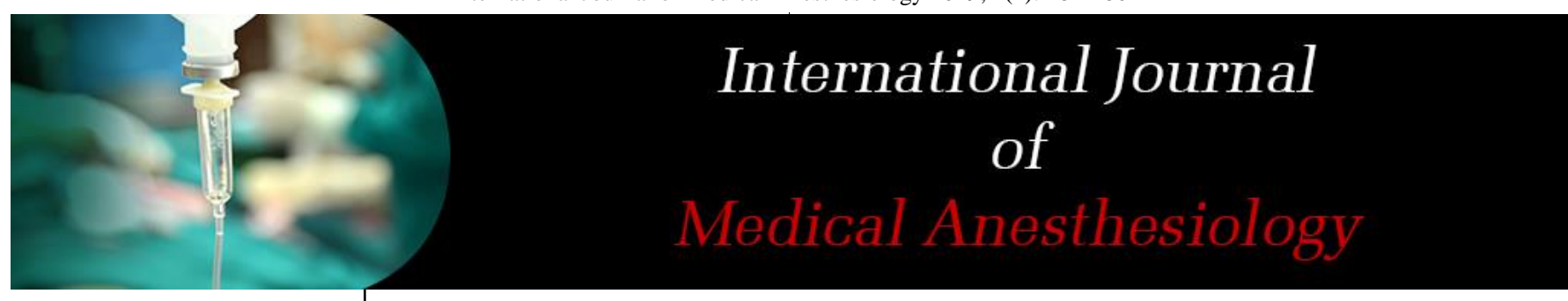

E-ISSN: 2664-3774

P-ISSN: 2664-3766

www.anesthesiologypaper.com

IJMA 2019; 2(2): 182-186

Received: 25-05-2019

Accepted: 28-06-2019

Kumar Abhishek

Assistant Professor,

Department of

Anaesthesiology (Trauma

Critical Care), Rajendra

Institute of Medical Sciences,

Jharkhand, India

Amol Bhalerao

Assistant Professor,

Department of

Anaesthesiology, Rural

Medical College, PIMS, Loni,

Maharashtra, India

Yogita Anarase

Assistant Professor,

Department of

Anaesthesiology, Rural

Medical College, PIMS, Loni,

Maharashtra, India

Smita Mokal

Assistant Professor,

Department of Physiology,

Rural Medical College, PIMS,

Loni, Maharashtra, India
Corresponding Author:

Amol Bhalerao

Assistant Professor,

Department of

Anaesthesiology, Rural

Medical College, PIMS, Loni,

Maharashtra, India

\title{
Efficacy of intravenous dexmedetomidine for attenuation of hemodynamic stress response to laryngoscopy and intubation
}

Kumar Abhishek, Amol Bhalerao, Yogita Anarase and Smita Mokal

DOI: https://doi.org/10.33545/26643766.2019.v2.i2c.49

\section{Abstract}

Background: Hemodynamic variation during laryngoscopy and tracheal intubation with reflex increase in sympathetic and sympathoadrenal activity is always matter of major concern for anesthesiologist, which may result in catastrophic effect, such as tachycardia, hypertension, myocardial ischemia, cardiac arrhythmia or cerebrovascular accident. To attunate haemodynamic response various drug such as lignocaine, opioids, nitroprusside, nitroglycerine, verapamil, nifedipine, esmolol has been used. Alpha-2 adrenergic agonist decrease sympathetic tone and obtunding hemodynamic response to noxious stimulation and prevent overall hemodynamic variability.

Aims and objectives: To study the efficacy of iv dexmedetomidine for attenuating stress responses to laryngoscopy and intubation.

Materials and Methods: Eighty patients, ASA grade I/II, undergoing routine general anesthesia were randomly premedicated by i.v. dexmedetomidine $(1 \mu \mathrm{g} / \mathrm{kg}$ in $50 \mathrm{cc}$ NS) or saline via infusion pump over 10 min. Heart rate (HR), mean arterial pressure (MAP) were measured before, after the premedication, after propofol, after succinylcholine, at laryngoscopy, immediately after intubation and then $1 \mathrm{~min}, 3 \mathrm{~min}$ and $5 \mathrm{~min}$ after intubation.

Results: The demographic data was comparable in both groups. After intubation the increase in heart rate was more in group $\mathrm{C}$ than group $\mathrm{D}(p<0.0001)$ at laryngoscopy and after intubation thus showed less fluctuation of HR in the group D than in the group $C$. The increase in MAP in the group $C$ at laryngoscopy and intubation was higher than that in the group $\mathrm{D}(p<0.0001)$ and exceeded the baseline value $(p<0.05)$ Thus the pressor response to laryngoscopy and intubation were effectively decreased by dexmedetomidine and were statistically highly significant on comparison to group $\mathrm{C}(p<0.05)$.

Conclusion: A single preanesthetic dose of $\mathrm{i} v$ dexmedetomidine $1 \mathrm{ug} / \mathrm{kg}$ is advantageous as it is found to be effective in attenuating the haemodynamic response of laryngoscopy and intubation and prevent its adverse effect.

Keywords: $\alpha 2$ adrenoreceptor, dexmedetomidine, hemodynamic, sympathoadrenal response, intubation

\section{Introduction}

Laryngoscopy and endotracheal intubation are consider as most critical events during general anesthesia as they provoke a transist but marked, sympathetic and sympathoadrenal response ${ }^{[1]}$. So, anaesthesiologist is always worried about this pressor response which leads to abnormal circulatory reaction which may be severe or prolonged ${ }^{[2]}$. The circulatory response in the form of increased heart rate and raised blood pressure usually occurs for short duration and is unpredictable. This transient increase in blood pressure and pulse rate does not cause any harm in healthy individuals but may create problem in patients with myocardial insufficiency or cerebrovascular disease ${ }^{[3]}$ which may further cause complications like pulmonary oedema, myocardial infarction or cerebrovascular accidents ${ }^{[4,5]}$ Pressor response is exaggerated in hypertensive patients even though made normotensive with antihypertensive medications ${ }^{[6]}$ and reflects intraoperatively with complications like myocardial infarction, acute left ventricular failure ${ }^{[7]}$, arrhythmias and intracranial bleed ${ }^{[8]}$. Several techniques have been studied to attenuate this stress response, but none of them are completely satisfactory. Hence, there is a constant search to attenuate the hemodynamic response to laryngoscopy and endotracheal intubation. Modern anesthesia practices, therefore, plan to prevent sympathetic discharge and provide hemodynamic stability perioperatively. As intravenous induction agents are not able to blunt stress response to laryngoscopy and endotracheal intubation, we have to add other pharmacological agents like lidocaine, sodium nitroprusside, calcium channel blockers, nitro-glycerine, beta blockers, inhalational anaesthetic agents, ACE inhibitors.

In last few years, a great enthusiasm has been shown toward the use of $\alpha 2$ agonists in anesthesia practice because of their anxiolytic, sedative, sympatholytic, and analgesic-sparing properties Dexmedetomidine is a selective $\alpha 2$ agonist with 8 times more affinity for $\alpha 2$ adrenergic receptors 
compared to clonidine and possesses all the properties of $\alpha 2$ agonist without respiratory depression ${ }^{[9,10]}$. Intravenous use of dexmedetomidine in the perioperative period had been found to decrease serum catecholamine levels by $90 \%{ }^{[11]}$, to blunt the hemodynamic response to laryngoscopy, tracheal intubation, pneumoperitoneum and extubation ${ }^{[12]}$ to provide sedation without respiratory depression and to decrease postoperative analgesic requirement. ${ }^{[13]}$ This study was undertaken to assess efficacy of intravenous dexmedetomidine $(1 \mu \mathrm{g} / \mathrm{kg})$ infusion in obtunding the pressor response to laryngoscopy and tracheal intubation.

\section{Materials and Methods}

This double blind, randomized, case control study was carried out 80 patients after approval of institutional ethical committee in tertiary care hospital. Patient aged between 18 and 55 years American Society of Anesthesiologists (ASA) physical status I and II undergoing elective surgery under general anesthesia were enrolled in this study. The primary aim of this study is to compare the efficacy of iv dexmedetomidine in the dose of $(1 \mu \mathrm{g} / \mathrm{kg}$ body weight $)$ in attenuating the pressor response to laryngoscopy and endotracheal intubation. Patients were randomly allotted into two groups, group C (Control group) and group D (dexmedetomidine group) with 40 patients in each group. In group D patients were pre-medicated with a single dose of dexmedetomidine $1 \mu \mathrm{g} / \mathrm{kg}$ and the same amount of saline was given to the patient in group C. Patients were excluded with H/O hypertension, coronary, cerebral diseases, peripheral vascular diseases, neurological disorder, endocrinal disorder, hepatic and renal diseases, patients on drugs such as $\beta$ blockers or calcium channel blockers, Obese patients, anticipated difficult airway, Patient requiring more than one attempt of intubation, History suggestive of sensitivity to study drugs, pregnant, lactating mother. Patient fulfilling inclusion criteria were included in this study. All patients were premedicated with tablet alprazolam $0.5 \mathrm{mg}$ at bedtime the night before surgery. They were kept nil orally $10 \mathrm{pm}$ onwards on the previous night. On arrival of the patient in the operating room baseline parameters such as heart rate (HR), mean arterial pressure (MAP), respiratory rate (RR), and oxygen saturation (SpO2) were recorded. All patients were prehydrated with $500 \mathrm{ml}$ of Ringer's lactate solution. Monitoring included three lead ECG, plethysmographic pulse oximeter, capnometry, noninvasive arterial pressure was performed. The observations were made by the same observer in all the patients so as to avoid observer bias. Patients were randomly allocated into two groups. Randomization was done by computer generated randomization table using random sequence was generated by random allocation software. Group D received single bolus IV dose of dexmedetomidine $(1 \mu \mathrm{g} / \mathrm{kg})$ diluted upto $50 \mathrm{ml}$ over $10 \mathrm{~min}$ by infusion pump as pre-medication and Group $C(n=40)$ received same volume of normal saline $(50 \mathrm{ml})$ as pre-medication via infusion and the infusion was completed $10 \mathrm{~min}$ before induction. Syringe containing premedication (either dexmedetomidine or normal saline) was prepared by a team member who was not involved in the data recording. All the patients in both group were premedicated with injection glycopyrrolate $0.004 \mathrm{mg} / \mathrm{kg} \mathrm{IV}$, injection Ondansetron $0.08 \mathrm{mg} / \mathrm{kg} \mathrm{IV}$, injection midazolam $0.02 \mathrm{mg} / \mathrm{kg} \mathrm{IV}$, and injection fentanyl $1 \mathrm{mcg} / \mathrm{kg}$ IV before preoxygenation. Ramsay sedation scale score was employed for assessing the sedation before induction of anesthesia in both the groups $(1=$ anxious, agitated and restless, $2=$ awake, cooperative, tranquil and oriented, $3=$ responds to verbal commands, $4=$ brisk response to loud noise, $5=$ sluggish response to loud noise, $6=$ no response to loud noise). After preoxygenation, all patients were induced with injection propofol solution at dose of $2 \mathrm{mg} / \mathrm{kg}$ iv till loss of the eye lash reflex occurred. Endotracheal intubation was facilitated with $2 \mathrm{mg} / \mathrm{kg}$ of succinylcholine given IV $1 \mathrm{~min}$ prior to laryngoscopy and intubation. Laryngoscopy was performed using Macintosh blade size 3 and intubation using the intratracheal tube (size 7.5-8 mm/cuffed) were carried out by a senior anesthesiologist or by a 2-year trained resident in anesthesiology, After intubation tube connected to closed circuit bilateral equal air entry confirmed, endotracheal tube was fixed. No surgical or any other stimulus was applied during $10 \mathrm{~min}$ of study period and vecuronium was the only additional drug given during this period. Anesthesia was maintained using 33\% oxygen and $66 \%$ nitrous oxide with isoflurane and vecuronium. At the end of the procedure, patients were reversed with an injection neostigmine $0.05 \mathrm{mg} / \mathrm{kg} \quad \mathrm{IV}$ and injection glycopyrrolate $0.08 \mathrm{mg} / \mathrm{kg}$ IV. Patients were extubated when they regained reflexes and consciousness. Hemodynamic parameter (HR, MAP) were recorded at following time interval:

- T0: Baseline on OT table

- T1: $10 \mathrm{~min}$ after pre-medication.

- T2: 30 seconds after propofol.

- T3: 30 second after succinylcholine at laryngoscopy.

- T4: immediately after intubation.

- T5: at 1 min after intubation.

- T6: at 3 min after intubation

- T7: at 5 min after intubation

\section{Statistical analysis}

The sample size was calculated by power analysis of a pilot study. A sample size of 27 patients per group was required to detect a $20 \%$ change in heart rate and mean arterial blood pressure between baseline and intubation time, with a power of $90 \%$ at the $5 \%$ significance level. To account for possible loss, sample size 40 in each group was decided. Data are expressed as the mean \pm standard deviation. Nominal categorical data among study groups were compared using the chi-square test. Independent $t^{-}$test was used to compare the study group and the control group. Comparison of groups from baseline was done by Wilcoxon sign rank test. The statistical software SPSS 16 (SPSS 16 Inc., Chicago, IL, USA) was used for statistical analysis of data. A p value $<0.05$ was consider significant.

\section{Result}

The both groups were comparable in term of age, sex, weight, ASA physical status, duration of laryngoscopy and intubation (table1). It was decided to exclude those patients, who require more than one attempt for intubation. In our study all patients were intubated in first attempt and there was no exclusion and time taken for laryngoscopy and intubation was comparable in both groups. The changes in HR and MAP in both groups at different time interval are shown in fig 1. Base line (T0) HR and MAP was comparable in both groups. In group $\mathrm{D}$, there was statistically significant initial fall in $\mathrm{HR}$ after dexmedetomidine $(p<0.05)$. In both groups there was rise in HR, immediately after laryngoscopy and intubation (T4), 
remained raised for 3 min postintubation $(P<0.05)$. But this rise was statistically significantly more in group $\mathrm{C}$ from $\mathrm{T} 1-$ T5 as compared to group D $(P<0.05)$. Heart rate in both groups was almost near to the baseline values at (T6) $(P>0.05)$. The maximum increases in $\mathrm{HR}$ in group $\mathrm{C}$ was $31.6 \%$ at T4 and in group D HR was not higher than preoperative value at all time and even at T4 time interval after intubation. No statistical significance was noted in MAP between groups at baseline, 3rd and 5th min after intubation. The maximum increase in MAP was $9.5 \%$ at T4 in group $\mathrm{C}$. The MAP was increased significantly compared with preoperative value after intubation in the group $\mathrm{C}$ $(p<0.05)$ and was significantly higher than in group D from T1-T5 $(p<0.05)$. In the group D, MAP was not significantly higher than the preoperative value at all times. The dexmedetomidine group had a better control of heart rate and blood pressure than the control group [Table $2 \& 3$ ]. No incidence of hypotension or bradycardia requiring intervention was reported in both groups.

Table 1: Demographic profile of patient

\begin{tabular}{|c|c|c|c|}
\hline Parameter & Group C & Group D & P value \\
\hline Age & $35.20 \pm 13.43$ & $34.75 \pm 16.65$ & 0.825 \\
\hline Male/Female & $22 / 18$ & $21 / 19$ & \\
\hline Weight $(\mathrm{kg})$ & $73.42 \pm 13.51$ & $75.14 \pm 10.49$ & 0.654 \\
\hline Height $(\mathrm{cm})$ & $161.21 \pm 7.86$ & $163.140 \pm 6.30$ & 0.721 \\
\hline BMI $(\mathrm{kg} / \mathrm{m})^{2}$ & $26.23 \pm 3.33$ & $26.37 \pm 4.37$ & 0.864 \\
\hline $\begin{array}{c}\text { Laryngoscopy \& } \\
\text { Intubation time (sec) }\end{array}$ & $10.16 \pm 09.29$ & $10.76 .75 \pm 11.37$ & 0.757 \\
\hline
\end{tabular}

Table 2: Comparison of mean HR (beats/min) in both groups at various time intervals.

\begin{tabular}{|c|c|c|c|}
\hline Parameter & Group C & Group D & P-value \\
\hline T0 (min) & $84.91 \pm 06.50$ & $85.17 \pm 06.38$ & 0.8567 \\
\hline T1 (min) & $88.23 \pm 08.88$ & $74.78 \pm 07.95$ & $0.0324^{*}$ \\
\hline T2 (min) & $86.12 \pm 05.12$ & $74.12 \pm 06.23$ & $<0.0001^{* *}$ \\
\hline T3 (min) & $85.31 \pm 07.37$ & $73.91 \pm 08.93$ & $<0.0001^{* *}$ \\
\hline T4 (min) & $111.75 \pm 05.76$ & $82.25 \pm 06.29$ & $<0.0001^{* *}$ \\
\hline T5 (min) & $98.13 \pm 03.59$ & $80.25 \pm 04.23$ & $<0.0001^{* *}$ \\
\hline T6 (min) & $86.25 \pm 06.25$ & $79.75 \pm 03.54$ & $0.0363^{*}$ \\
\hline T7 (min) & $80.01 \pm 07.57$ & $78.78 \pm 09.97$ & 0.5846 \\
\hline
\end{tabular}

Data expressed as mean \pm SD. $* P<0.05$ statistically significant, $* * P<0.001$ statistically highly significant. T0: Baseline on OT table, T1: 10 min after premedication, T2: 30 seconds after propofol, T3: 30 second after succinylcholine at laryngoscopy, T4: immediately after intubation, T5: at $1 \mathrm{~min}$ after intubation, T6: at $3 \mathrm{~min}$ after intubation, T7: at $5 \mathrm{~min}$ after intubation.

Table 3: Comparison of mean arterial blood pressure in both groups at various time intervals.

\begin{tabular}{|c|c|c|c|}
\hline Parameter & Group C & Group D & P-value \\
\hline T0 (min) & $92.50 \pm 08.51$ & $93.17 \pm 07.35$ & 0.8564 \\
\hline T1 (min) & $95.53 \pm 08.88$ & $88.73 \pm 07.96$ & $0.0483^{*}$ \\
\hline T2 (min) & $96.35 \pm 07.59$ & $84.71 \pm 06.98$ & $<0.0001^{* *}$ \\
\hline T3 (min) & $98.51 \pm 10.37$ & $85.91 \pm 09.73$ & $<0.0001^{* *}$ \\
\hline T4 (min) & $101.25 \pm 13.76$ & $86.25 \pm 11.29$ & $<0.0001^{* *}$ \\
\hline T5 (min) & $92.02 \pm 11.19$ & $84.12 \pm 09.23$ & $0.0397^{*}$ \\
\hline T6 (min) & $84.92 \pm 10.08$ & $83.75 \pm 11.58$ & 0.6968 \\
\hline T7 (min) & $83.56 \pm 11.47$ & $82.89 \pm 12.17$ & 0.7468 \\
\hline
\end{tabular}

Data expressed as mean \pm SD. $* P<0.05$ statistically significant, $* * P<0.001$ statistically highly significant. T0:
Baseline on OT table, T1: 10 min after pre-medication., T2: 30 seconds after propofol, T3: 30 second after succinylcholine at laryngoscopy, T4: immediately after intubation, T5: at $1 \mathrm{~min}$ after intubation, T6: at $3 \mathrm{~min}$ after intubation, T7: at 5 min after intubation.

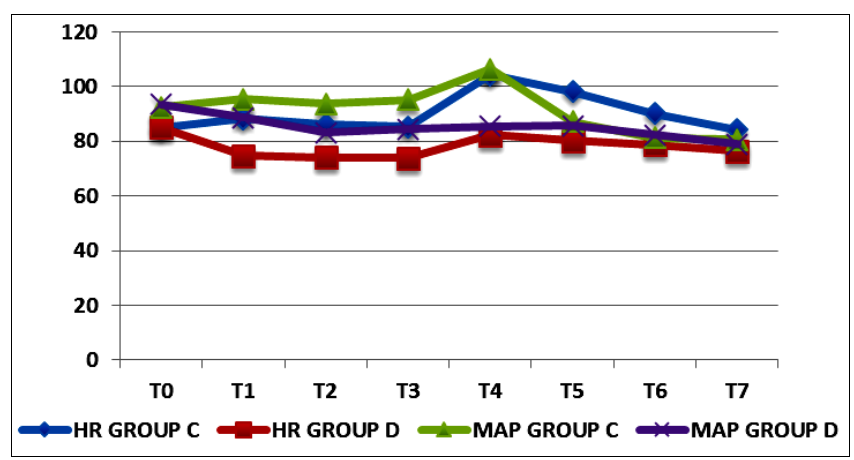

Fig 1: Mean intra-operative HR and Mean MAP at each time point for two groups

\section{Discussion}

Laryngoscopy and intubation are most stressful conditions to which the patient is subjected following induction of anaesthesia, is almost always associated with hemodynamic changes due to intense autonomic reflex response. This increased in sympathoadrenal activity may result in increase in heart rate, blood pressure, intracranial tension, intraocular pressure and cardiac arrhythmias. Transitory hypertension and tachycardia may predispose to the development of pulmonary edema, and myocardial insufficiency, cardiac asystole, coronary and cerebral infarction. Various agents such as opioids, beta adrenergic blockers, calcium channel antagonists, and clonidine have been used to blunt the hemodynamic response to laryngoscopy and intubation, but they all had limitations. Dexmedetomidine is a $\alpha 2$ agonist with sedative, sympatholytic, and analgesic properties and hence it can be a very useful adjuvant in anesthesia as stress response buster. Pretreatment with dexmedetomidine attenuates hemodynamic response to laryngoscopy and intubation. Several researchers $\left.{ }^{[1}{ }^{14-18}\right]$ have used 0.5-1 $\mathrm{mcg} / \mathrm{kg}$ of dexmedetomidine to attenuate stress response to intubation. A biphasic cardiovascular response has been described after the administration of dexmedetomidine ${ }^{[19]}$. A bolus dose of $1 \mu \mathrm{g} / \mathrm{kg}$ results in a transient increase in BP and reflex decrease in HR in young healthy patients. Initial response is due to $\alpha 2$ receptor stimulation of vascular smooth muscle. This response can be markedly decreased by slow infusion over $10 \mathrm{~min}$. In our study, this effect was not noticed due to the slow infusion of the dexmedetomidine over 10 min via infusion pump.

Dexmedetomidine in locus ceruleus stimulation of $\alpha 2 \mathrm{~A}$ and $\alpha 2 \mathrm{C}$ cause sedation. Several researchers ${ }^{[15,17,20-21]}$ have reported that dexmedetomidine infusion produces sedation which mimics normal sleep, patients are arousable to verbal commands, and it lacks respiratory depression. In present study, injection midazolam and injection fentanyl used as premedication, in the pre induction period of all patients in group $\mathrm{C}$ had sedation score 2 while it was 3 in group D, it was due to additional sedative action of dexmedetomidine. None of the patients in either group had respiratory depression or fall in $\mathrm{SpO} 2$.

Propofol is favourable induction agent with cardiovascular depressive property and is more effective at suppressing stress hormone release than thiopental. In our study propofol 
dose requirement was $16 \%$ less in group D as compared to group $\mathrm{C}(P<0.001)$. In previous study thiopental was used as induction agent and induction dose of which was significantly decreased in dexmedetomidine group than control. Keniya et al, ${ }^{[15]}$ Scheinin et al. ${ }^{[16]}$ and Bajwa et al. [17] reported decreased thiopentone requirement for induction of anesthesia in the dexmedetomidine group.

In group D following infusion of dexmedetomidine, there was $12.35 \%$ reduction in heart rate and $4.76 \%$ in MAP, while in group $\mathrm{C}$ there was no change in mean HR and mean MAP as compare to basal parameter. Observations of our study were similar to the observations of other studies, which can be explained on the basis of decreased central nervous system sympathetic activity ${ }^{[14-15,17,22]}$. Few authors noted a significant fall in HR in the dexmedetomidine group and an insignificant fall in MAP ${ }^{[1,18]}$.

Dexmedetomidine by activation of both $\alpha 2 \mathrm{~A}$ and $\alpha 2 \mathrm{C}$ receptors in the spinal cord directly reduce pain transmission by reducing the release of substance P. In both groups there was increase in HR and MAP with intubation and laryngoscopy. Increase in HR and MAP was maximum immediately after intubation in group $\mathrm{C}$ when compare to baseline. Maximum increase in mean heart rate was around $31.6 \%$ in group $\mathrm{C}(P<0.05)$ when compared to baseline and maximum increase in mean arterial pressure was $9.5 \%$ in group $\mathrm{C}(P<0.05)$. In group $\mathrm{D}$ variation in hemodynamic parameter due to intubation response was less as compare to group $\mathrm{C}$ mainly due sympatholytic activity of dexmedetomidine. Similar result was obtained in previous study ${ }^{[14-18]}$.

Studies suggest that perioperative use of dexmedetomidine may result in a decreased risk of adverse cardiac events, including myocardial ischemia ${ }^{[23]}$. $\alpha$ adrenoreceptors stimulation can beneficially modulate coronary blood flow during myocardial ischemia by preventing transmural redistribution of blood flow away from the ischemic endocardium by specific epicardial vasoconstrictive effects, leading to improvement in endocardial perfusion (the reverse steal effect) and by decreasing HR. This property along with hemodynamic stability and attenuation of intubation response makes dexmedetomidine an ideal anesthetic adjuvant, particularly for patients undergoing coronary bypass grafting.

No serious side effects like hypotension and bradycardia were observed during study period in either group. This may be due to adequate plasma volume expansion and inj glycopyrrolate used as premedication. The change in hemodynamic parameter due to intubation stress response was less affected in dexmedetomidine group than control. Thus dexmedetomidine provided better protection against unwanted hemodynamic side effect of intubation and laryngoscopy by blunting the stress response than placebo.

\section{Limitation}

We did not measure the plasma epinephrine levels and extubation response. More studies need to be done in high risk hypertensive and cardiac patient as dexmedetomidine can be more beneficial in such patients.

\section{Conclusion}

We conclude that IV dexmedetomidine $1 \mathrm{mcg} / \mathrm{kg}$ given slowly over $10 \mathrm{~min}$ as premedication had been shown to be effective and safe in attenuating stress induced sympathoadrenal response thus protecting the patient from noxious sympathetic stimulation and hemodynamic changes during laryngoscopy and intubation to prevent its consequences without any significant side effect.

\section{References}

1. Sulaiman S, Karthekeyan RB, Vakamudi M, Sundar AS, Ravullapalli H, Gandham R et al. The effects of dexmedetomidine on attenuation of stress response to endotracheal intubation in patients undergoing elective off-pump coronary artery bypass grafting. Ann Card Anaesth. 2012; 15:39-43.

2. King BD, Harris LC, Greifenstein FE, Elder JD, Dripps RD. Reflex circulatory responses to direct laryngoscopy and tracheal intubation performed during general anesthesia. Anesthesiology. 1951; 12:556-66.

3. Kovac AL. Controlling the haemodynamic response to laryngoscopy and endotracheal intubation. Journal of Clinical Anaesthesia. 1996; 8:63-79.

4. Prys-Roberts C, Green LT, Meloche R, Foex P. Studies of anaesthesia in relation to hypertension II. Haemodynamic consequences of induction and endotracheal intubation. Br J Anaesth. 1971; 43:531-47.

5. Dalton B, Guiney T. Myocardial ischemia from tachycardia and hypertension in coronary heart disease Patients undergoing anaesthesia. Boston: Ann Mtg American Society of Anaesthesiologists, 1972, 201-2.

6. Cedric Preys Roberts. Anaesthesia and hypertension. $\mathrm{Br}$ J Anaesth. 1984; 56:711-24.

7. Fox EJ, Sklar GS, Hill CH, Villanue Var, King BD. Complications related to the pressor response to endotracheal intubation. Anaesthesiology. 1977; 47:524-5.

8. Ronald Miller D. Miller's Anesthesia volume 2 Seventh edition, 2010.

9. Hall JE, Uhrich TD, Barney JA, Arain SR, Ebert TJ. Sedative, amnestic, and analgesic properties of small-dose dexmedetomidine infusions. Anesth Analg. 2000; 90:699-705.

10. Carollo DS, Nossaman BD, Ramadhyani U. Dexmedetomidine: A review of clinical applications. Curr Opin Anaesthesiol. 2008; 21:457-61.

11. Bloor BC, Ward DS, Belleville JP, Maze M. Effects of intravenous dexmedetomidine in humans. II. Hemodynamic changes. Anesthesiology. 1992; 77:1134-42.

12. Isik B, Arslan M, Özsoylar O, Akçabay M. The effects of $\alpha 2$-adrenergic receptor agonist dexmedetomidine on hemodynamic response in direct laryngoscopy. Open Otorhinolaryngol J. 2007; 1:5-11.

13. Gurbet A, Basagan-Mogol E, Turker G, Ugun F, Kaya $\mathrm{FN}$, Ozcan $\mathrm{B}$ et al. Intraoperative infusion of dexmedetomidine reduces perioperative analgesic requirements. Can J Anaesth. 2006; 53:646-52.

14. Menda F, Köner O, Sayin M, Türe H, Imer P, Aykaç B et al. Dexmedetomidine as an adjunct to anesthetic induction to attenuate hemodynamic response to endotracheal intubation in patients undergoing fasttrack CABG. Ann Card Anaesth. 2010; 13:16-21.

15. Keniya VM, Ladi S, Naphade R. Dexmedetomidine attenuates sympathoadrenal response to tracheal intubation and reduces perioperative anaesthetic requirement. Indian J Anaesth. 2011; 55:352-7.

16. Scheinin B, Lindgren L, Randell T, Scheinin H, Scheinin M. Dexmedetomidine attenuates 
sympathoadrenal responses to tracheal intubation and reduces the need for thiopentone and peroperative fentanyl. Br J Anaesth. 1992; 68:126-31.

17. Bajwa SJ, Kaur J, Singh A, Parmar S, Singh G, Kulshrestha A et al. Attenuation of pressor response and dose sparing of opioids and anaesthetics with preoperative dexmedetomidine. Indian J Anaesth. 2012; 56:123-8.

18. Pipanmekaporn T, Punjasawadwong Y, Charuluxananan S, Lapisatepun W, Bunburaphong P. The effect of prophylactic dexmedetomidine on hemodynamic disturbances to double-lumen endotracheal intubation: A prospective, randomized, double-blind and placebo-controlled trial. Anesthesiol Res Pract. 2013; 2013:236089.

19. Bloor BC, Ward DS, Belleville JP, Maze M. Effects of intravenous dexmedetomidine in humans. II. Haemodynamic changes. Anaesthesiology. 1992; 77:1134-42.

20. Hall JE, Uhrich TD, Barney JA, Arain SR, Ebert TJ. Sedative, amnestic, and analgesic properties of smalldose dexmedetomidine infusions. Anesth Analg. 2000; 90:699-705.

21. Guler G, Akin A, Tosun Z, Eskitascoglu E, Mizrak A, Boyaci A et al. Singledose dexmedetomidine attenuates airway and circulatory reflexes during extubation. Acta Anaesthesiol Scand. 2005; 49:1088-91.

22. Carollo DS, Nossaman BD, Ramadhyani U. Dexmedetomidine: A review of clinical applications. Curr Opin Anaesthesiol. 2008; 21:457-61.

23. Talke P, Li J, Jain U, Leung J, Drasner K, Hollenberg $\mathrm{M}$ et al. Effects of perioperative dexmedetomidine infusion in patients undergoing vascular surgery. The Study of Perioperative Ischemia Research Group. Anaesthesiology. 1995; 82:620-33. 